\title{
Saberes ambientais nos livros indígenas: uma proposta de educação ambiental a partir das árvores
}

\author{
Rafael Otávio Fares Ferreira ${ }^{1}$ \\ Alicy Madeira de Souza ${ }^{2}$
}

\section{RESUMO}

Tendo como referência principalmente três livros de autoria indígena: o Livro das Árvores (1997, dos povos Ticuna), Esta é a Terra Que Nós Plantamos (2007, dos povos Kiukuro), e o livro Curar (2008, povos Maxakali), este artigo é o resultado de uma pesquisa inicial que busca, a partir de saberes tradicionais indígenas sobre as árvores e noções trazidas da antropologia, como o perspectivismo ameríndio elaborado por Viveiros de Castro e a noção do Dono, propor dinâmicas para a educação ambiental. A partir de uma pesquisa teórica mas também aplicada, que buscou o diálogo entre o conhecimento desenvolvido pela Engenharia Ambiental e os saberes indígenas, foram propostas, e aqui apresentadas, oficinas que visam promover o conhecimento dos participantes tanto em relação ao que pensam os indígenas sobre as árvores quanto sobre as relações ecológicas que estes elaboram em seus saberes ambientais.

Palavras-chave: Educação ambiental. Saberes indígenas. Árvores.

\footnotetext{
${ }^{1}$ Graduado, Mestre e Doutor em Letras pela Universidade Federal de Minas Gerais - UFMG. É poeta e também professor e pesquisador da Universidade do Estado de Minas Gerais - UEMG, Unidade João Monlevade, MG, Brasil. E-mail: rafael.ferreira@uemg.br.

${ }^{2}$ Técnica em Segurança do Trabalho pelo SENAI. É graduanda em Engenharia Ambiental pela Universidade do Estado de Minas Gerais - UEMG, Unidade João Monlevade, MG, Brasil. E-mail: alicysouza.2631@hotmail.com.
} 


\title{
El conocimiento ambiental en los libros indígenas: una propuesta de educación ambiental basada en los árboles
}

\begin{abstract}
RESUMEN
Teniendo como referencia dos libros de autoría indígena: el Libro de los árboles (1997, de los pueblos Ticuna), Esta es la tierra que plantamos (2007, de los pueblos Kiukuro), y el libro Curar (2008, pueblos Maxakali), este artículo es el resultado de una investigación inicial que busca, partiendo del conocimiento tradicional indígena sobre árboles y nociones traídas desde la antropología, como el perspectivismo amerindio elaborado por Viveiros de Castro y la noción del Dueño, proponer dinámicas para la educación ambiental. Con base en una investigación teórica pero también aplicada, que buscó un diálogo entre el conocimiento desarrollado por la Ingeniería Ambiental y el conocimiento indígena, se propusieron, y aquí se presentan, talleres orientados a promover el conocimiento de los participantes tanto en relación a lo que piensan los indígenas de los árboles como acerca de las relaciones ecológicas que desarrollan en su conocimiento ambiental.
\end{abstract}

Keywords: Educación ambiental. Saberes indígenas. Árboles.

Artigo recebido em: 10/06/2020

Aceito em: 04/12/2020 


\section{INTRODUÇÃO}

Cada vez mais os cientistas têm apontado a importância da manutenção das florestas para as questões climáticas do planeta, por exemplo, em relação ao chamado aquecimento global (DANOWSKI e CASTRO, 2014). Além disso, as árvores desempenham um papel importante para a manutenção da vida do nosso planeta pois realizam serviços ecossistêmicos (controle de erosão, formação dos solos, regulação das quantidades de água, etc) e, mesmo que estas afirmações estejam em discussão, sabe-se que realizam a filtragem e a limpeza do ar atmosférico por meio da retenção dos gases dióxido de carbono $\left(\mathrm{CO}_{2}\right)$, reduzindo a incidência de doenças como asma, câncer de pele, além de doenças relacionadas ao estresse e, principalmente, fornecendo o gás oxigênio, essencial para a vida humana, através da fotossíntese (LARA e WEINSE, 2018).

Os seres humanos utilizam os recursos que as árvores fornecem, como a madeira, o carvão, os frutos, as flores e as matérias-primas para a fabricação de papel, além de outros produtos. Porém, com o crescimento populacional e o progresso desenfreado, ocorre uma rápida degradação dos recursos naturais como afirma Souza (1997):

O progresso tecnológico, a amplitude cada vez maior dos horizontes urbanos ante um aumento demográfico explosivo e o crescimento imperativo da produção agro-industrial, contribuem para a rápida destruição dos recursos naturais e desequilíbrio da natureza, principalmente nas regiões tropicais. (SOUZA, 1997, p. 6,)

Em Minas Gerais, estado onde vivemos e realizamos este trabalho, nos últimos anos, ocorreram dois dos maiores desastres ambientais da história da humanidade: o rompimento das barragens do Fundão em Mariana e o da Mina do Feijão em Brumadinho. No primeiro foram despejados 43,7 milhões de metros cúbicos de rejeitos atingindo o Rio Doce e percorrendo 663 quilômetros até chegar no mar. O bioma atingido foi a Mata Atlântica, considerada uma das florestas com maior biodiversidade do mundo. No segundo caso, foram 12 milhões de metros cúbicos, causando um enorme estrago ambiental, além de quase 300 mortes. Esses desastres prejudicaram e muito a fauna, a flora e o meio ambiente de suas regiões, além de provocarem danos irreparáveis para as pessoas que viviam nos lugares e causarem muitas mortes.

Assim, conclui-se que é urgente que a humanidade mude sua forma de lidar com as questões ambientais de maneira geral. Para isso, entendemos que é necessário que se desenvolvam práticas de educação ambiental para que as futuras gerações tenham maior 
consciência e respeito pelo meio ambiente. Porém, muitas vezes, estas práticas de educação ambiental acabam se tornando repetitivas e muito restritas à reciclagem de matérias e clichês de sustentabilidade que se repetem nas escolas.

Hoje sabemos que os povos indígenas são grandes responsáveis pela preservação das florestas no Brasil, conforme nos mostram os dados do ISA - Instituto Socioambiental ${ }^{3}$. Por isso, este trabalho busca trazer para a educação ambiental saberes tradicionais dos povos indígenas, que são grandes conhecedores não só das nossas árvores, mas das paisagens brasileiras em geral. Todavia, para isso é preciso questionar a falta de conhecimento nas universidades brasileiras, além do preconceito que muitas vezes as universidades e, portanto, os educadores, possuem em relação ao chamado saber tradicional dessas populações.

Os saberes indígenas, transmitidos de geração para geração, foram e continuam sendo considerados atrasados em relação à civilização ocidental e, consequentemente, em relação aos conhecimentos científicos, na medida em que são colocados como primitivos em nossa história. Como afirma o pensador Antônio Risério, houve uma corrente positivista oitocentista que realizou uma "construção ideológica (montada numa hábil e poderosa produção teórica de homologias entre a história da natureza e a história da sociedade) que acredita na realidade de uma trajetória unilinear presidindo à evolução da humanidade" (RISÉRIO, 1993, p. 26).

O que nos mostra o pensador Claude Lévi-Strauss (1976), em seu livro O Pensamento Selvagem, é que essas fronteiras tão aparentemente bem delineadas entre ciência e saber tradicional são mais borradas do que parecem. Dando mais nuances para essa dicotomia, é possível pensar que a ciência, em muitos casos baseada em conhecimentos empíricos, tinha e ainda tem métodos de pesquisa semelhantes aos de muitas práticas tradicionais, como as dos povos indígenas. Se, como se costuma pensar, a ciência no ocidente aparentemente se distanciou das sociedades tradicionais, notadamente mitológicas, os povos tradicionais, contudo, não estão de todo afastados de métodos de pesquisa concretos e empíricos. Essa é uma relação formal para cujo conhecimento Lévi-Strauss chamou a atenção em $O$ Pensamento Selvagem:

Os mitos e ritos oferecem como valor principal a ser preservado até hoje, de forma residual, modos de observação e de reflexão que foram (e sem dúvida permanecem) exatamente adaptados a descobertas de tipo determinado: as que a

\footnotetext{
${ }^{3}$ Maiores informações podem ser acesssadas neste link no site da instituição: https://www.socioambiental.org/pt-br/blog/blog-do-monitoramento/a-demarcacao-das-terras-indigenas-edecisiva-para-conter-o-desmatamento-e-manter-funcoes-climaticas-essenciais.
} 
natureza autorizava, a partir da organização e da exploração especulativa do mundo sensível em termos de sensível. Essa ciência do concreto devia ser, por essência, limitada a outros resultados além dos prometidos às ciências exatas e naturais, mas ela não foi menos científica, e seus resultados não foram menos reais. Assegurados dez mil anos antes dos outros, são sempre o substrato de nossa civilização (STRAUSS, 1976, p. 31).

Os métodos pelos quais os indígenas chegam a seus saberes possuem semelhanças com os métodos da chamada ciência moderna ocidental; ou seja, na medida em que se baseiam em um acúmulo de observações e experiências, os saberes indígenas são a acumulação de investigações do que o pensador vai chamar de ciência do concreto. $\mathrm{O}$ fato é que, mesmo associados às crenças religiosas, ou aos mitos, há muito conhecimento entre os indígenas sobre as relações entre os seres vivos e os ambientes (BERKES et al., 2000).

Quando se fala de sabedoria indígena tradicional, não se trata apenas dos distintos saberes acumulados através dos séculos de existência e civilização, mas também das formas distintas de ver o mundo; isto é, a visão holística pela qual a existência humana é descoberta pelas comunidades indígenas (CAVALLO, 2018). Neste trabalho, fruto de uma iniciação científica, não nos aprofundamos como gostaríamos nos conhecimentos antropológicos, mas procurou-se minimamente introduzir noções trazidas desta área do conhecimento por considerarmos esses estudos imprescindíveis para esse tipo de pesquisa, diversificando e dando um aporte antropológico para o trabalho do engenheiro ambiental e de outras áreas afins.

Os povos indígenas possuem uma relação de respeito com as árvores, como assinala o Livro das Árvores do povo Ticuna: "Uma árvore é diferente da outra. E cada árvore tem sua importância, seu valor. Essa variedade é que faz a floresta tão rica” (TICUNA, 1997, p. 11). Assim, como neste caso, este trabalho buscou identificar e catalogar os saberes indígenas em livros sobre as árvores, além de desenvolver metodologias que foram aplicadas em oficinas para crianças a fim de se obter resultados que relacionassem o conhecimento popular que as crianças possuem com os saberes indígenas, aliados, ainda, aos conhecimentos científicos da engenharia ambiental, com a proposta final de ser um instrumento para a educação ambiental.

\section{MÉTODOS E PROCEDIMENTOS}

Esta pesquisa caracteriza-se como de natureza aplicada, por seu interesse prático para a obtenção de resultados; com o objetivo explorativo de levantar informações sobre as 
árvores nos livros indígenas e o explicativo, de registrar e analisar os fenômenos estudados, buscando identificar suas causas por meio da interpretação possibilitada pelos métodos de caráter qualitativo.

Com base nos objetivos deste estudo, recorreu-se à pesquisa bibliográfica, tendo como principais referências o Livro das Árvores (1997), dos povos Ticuna, e Esta é a Terra Que Nós Plantamos (2007), dos povos Kiukuro; além de outros livros indígenas e artigos relacionados aos saberes ambientais indígenas com especial enfoque nas árvores, seus mitos, importância e utilização. Ademais, utilizaram-se pesquisas experimentais, realizadas por meio de oficinas de educação ambiental, com a intenção de trazer a relação da visão de mundo indígena com os animais e os conhecimentos dos participantes. Nesse sentido, foi usada a teoria desenvolvida pelo antropólogo Eduardo Viveiros de Castro, denominada Perspectivismo Ameríndio. A ideia central desta teoria é que os indígenas, para obterem seus saberes, precisam estar constantemente trocando de ponto de vista com os animais e com os seres com os quais eles convivem. Como afirma o próprio autor:

Todo ser a que se atribui um ponto de vista será assim sujeito, espírito; ou melhor, ali onde estiver o ponto de vista, também estará a posição de sujeito. Enquanto nossa cosmologia construcionista pode ser resumida na fórmula saussureana: o ponto de vista cria o objeto - o sujeito sendo a condição originária fixa de onde emana o ponto de vista -, o perspectivismo ameríndio procede segundo o princípio de que o ponto de vista cria o sujeito; será sujeito quem se encontrar ativado ou “agenciado" pelo ponto de vista. (CASTRO, 1996, p. 126)

Portanto, é ao se colocar no lugar do outro, mesmo um outro ser que não seja humano, que um indígena aprende. E este foi o princípio utilizado nas dinâmicas de educação ambiental propostas nas escolas, isto é, de que as crianças se colocassem no lugar das árvores.

Em parceria com a Secretaria de Meio Ambiente da cidade de Barão de Cocais - MG, foi realizada a Semana da Árvore no Parque Municipal Fazenda da Soledade (Figura 1), entre os dias 16 e 19 de setembro, em que o público alvo foram os alunos das escolas públicas do próprio município. A escolha dessas datas se deu em virtude da comemoração do dia da árvore em 21 de setembro. 
Figura 1: Fazenda da Soledade

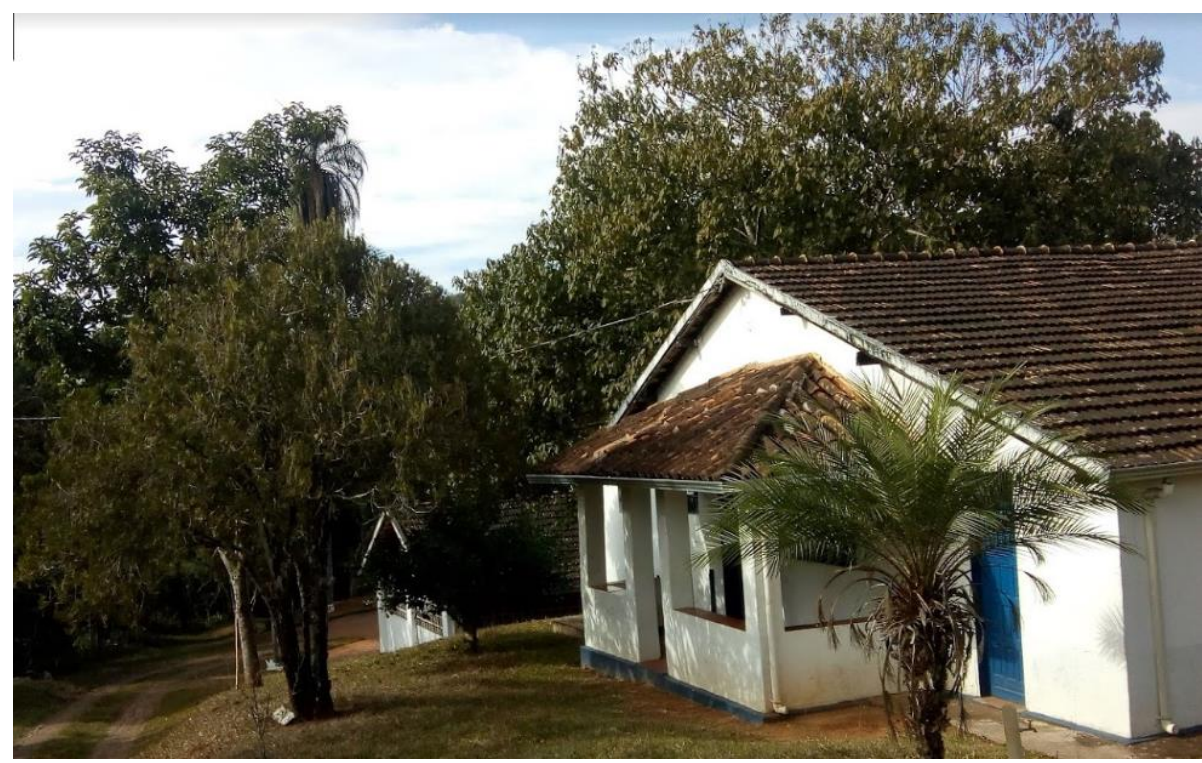

Fonte: Google Imagens (2018).

Primeiramente foram definidas as faixas etárias que iriam participar das oficinas, a quantidade de alunos e quais atividades seriam realizadas. Posteriormente, após a divulgação do evento pela prefeitura, foi obtida a informação de quais escolas iriam comparecer e em quais horários. A tabela a seguir mostra as atividades que foram propostas de acordo com a faixa etária das crianças participantes.

Tabela 1: Atividades realizadas na Semana da Árvore

\begin{tabular}{l|c}
\multicolumn{1}{c|}{ Atividade } & Faixa etária \\
\hline $\begin{array}{l}\text { Passeio com as crianças para conhecer as árvores da Fazenda da } \\
\text { Soledade }\end{array}$ & Todas \\
\hline $\begin{array}{l}\text { Roda de conversa contando mais histórias sobre as árvores e } \\
\text { associando-as aos índios }\end{array}$ & Todas \\
\hline Dinâmica da música "Árvore" de Arnaldo Antunes & $5-8$ anos \\
\hline Dinâmica: As “Árvores e seus donos" & $5-8$ anos \\
\hline Mostra do documentário: A gente luta, mas come fruta. & $9-14$ anos \\
\hline Oficina de frases: "Como os índios ajudam a proteger as florestas?" & $9-14$ anos \\
\hline Oficina: Colagem com folhas & 5-8 anos \\
\hline Dinâmica: "Qual árvore você seria?” & 5-8 anos \\
\hline
\end{tabular}

Fonte: Autoria própria.

Durante o passeio com as crianças pela Fazenda da Soledade, foram escolhidas algumas árvores que existem no local e contadas histórias acerca da origem de seus nomes 
populares; lendas indígenas e explicações sobre como os índios as utilizam, além de ensinar como é feita a identificação de uma árvore utilizando-se a coletânea dos livros Árvores Brasileiras.

Para cada faixa etária, diferentes metodologias foram adotadas; entre as crianças mais jovens, de 5 a 8 anos, foram propostas atividades que estimulassem a criação de desenhos relacionados à temática ambiental e aos saberes indígenas. Com crianças entre 9 e 14 anos, com a intenção de estimular um pensamento mais crítico sobre a importância dos indígenas na preservação do meio ambiente, foi exibido o documentário A gente luta mas come fruta, que retrata o manejo agroflorestal realizado pelos Ashaninka da aldeia Apiwtxa no Rio Amônia, Acre. O filme mostra o trabalho da comunidade para recuperar os recursos da sua reserva e repovoar seus rios e suas matas com espécies nativas.

Além das atividades propostas, foram utilizados cartazes para ilustrar histórias de árvores nativas do Brasil citadas em livros indígenas, tais como Açaí, Jacarandá, Ipê Amarelo e Urucum.

\section{RESULTADOS E DISCUSSÃO}

A partir das pesquisas bibliográficas nos livros de autoria indígena, é possível notar que as árvores são muito citadas em todas as obras utilizadas. Sua importância, suas características físicas e utilidades são retratadas pelos povos Maxakalí, Ticuna, Kuikuro e Karipuna.

Para os Ticuna, povos que vivem entre o Brasil, a Colômbia e o Peru, e contam com uma população de cerca de 80.000 pessoas, o Rio Solimões surgiu de uma árvore de Samaumeira, como mostra a narrativa abaixo:

\section{A SAMAUMEIRA QUE ESCURECIA O MUNDO}

No princípio, estava tudo escuro, sempre frio e sempre noite. Uma enorme sumaumeira, wotchine, fechava o mundo, e por isso não entrava claridade na terra. Yo'i e Ipi ficaram preocupados. Tinham que fazer alguma coisa. Pegaram um caroço de araratucupi, tcha, e atiraram na árvore para ver se existia luz do outro lado. Através de um buraquinho, os irmãos enxergaram uma preguiça-real que prendia lá no céu os galhos da samaumeira. Jogaram muitos e muitos caroços e assim criaram as estrelas. Mas ainda não havia claridade. Yo'i e Ipi ficaram pensando e decidiram convidar todos os animais da mata para ajudarem a derrubar a árvore. Mas nenhum deles conseguiu, nem o pica-pau. Resolveram, então, oferecer a irmã Aicüna em casamento para quem jogasse formigas-de-fogo nos olhos da preguiça-real. O quatipuru tentou, mas voltou no meio do caminho. Finalmente aquele quatipuruzinho bem pequeno, taine, conseguiu subir. Jogou as formigas e a preguiça soltou o céu. A árvore caiu e a luz apareceu. Taine casou-se 
com Aicüna. Do tronco da samaumeira caída formou-se o rio Solimões. De seus galhos surgiram outros rios e os igarapés. (TICUNA, 1997, p.14)

Pelo trecho é possível notar a relação entre as árvores e a genealogia, além de explicar a origem da região onde eles vivem: o rio Solimões. Os Ticuna também contam que, através da árvore de Jenipapo, surgiram os povos de diversas etnias como os negros e os brancos:

Tetchi arü Ngu'i era mulher de Yo'i, mas ficou gestante de Ipi. Yo'i não gostou disso e resolveu castigar o irmão. Assim que a criança nasceu, Yo'i mandou Ipi buscar jenipapo, $e$, para pintar o menino. Quando Ipi subiu na árvore, ela começou a crescer, crescer, quase alcançando o céu. Ipi sofreu muito, mas por fim conseguiu apanhar uma fruta. Desceu da árvore transformado em tucandeira, trazendo o jenipapo na boca. Yo'i mandou Ipi ralar a fruta sem parar. Ele ralou, ralou, ralou, até que ralou seu próprio corpo. Tetchi arü Ngu 'i pegou o sumo do jenipapo e pintou o filho. Depois jogou a borra no igarapé Eware. A borra do jenipapo desceu pela água e foi parar num lugar com muito ouro. Depois tornou a subir, já transformada em peixinhos, numa grande piracema. Quando a piracema passou, $Y o$ ' $i$ fez um caniço e foi pescar, usando caroço de tucumã maduro. Mas os peixes, quando caíam na terra, viravam animais: queixada, anta, veado, caititu e muitos outros. Aí Yo'i usou isca de macaxeira, e com essa isca os peixinhos se transformavam em gente. Yo'i aproveitou e pescou muita gente. Mas seu irmão não estava entre essas pessoas. Yo'i, então, entregou o caniço para Tetchi arü Ngu'i e ela conseguiu fisgar um peixinho que tinha uma mancha de ouro na testa. Era o Ipi. Ipi saltou em terra, pegou o caniço e pescou os peruanos e outros povos. Esse pessoal foi embora com Ipi para o lado onde o sol se põe. Da gente pescada por $Y o$ ' $i$ descendem os Ticuna e também outros povos que rumaram para o lado onde o sol nasce, inclusive os brancos e os negros. (TICUNA, 1997, p. 14)

Já em outra obra, de outra etnia que vive em outro bioma brasileiro: o cerrado, os Kuikuro nos apresentam, no livro Esta é a terra que nós plantamos, a importância e a utilidade da árvore Buriti para o seu povo:

Nós usamos o buriti: sua casca e seu fio também. Fazemos cestos com a casca e o fio de buriti. Vamos buscar esse recurso de canoa. A planta do buriti depois de ser cortada, volta a nascer. Nós retiramos folhas de buriti pequeno, pois é mais adequado para fazer cestos. (KUIKURO, 2007, p. 73)

O Buriti pode ser encontrado em diversas partes do país e faz parte do dia a dia de diversas etnias brasileiras e também é citado pelos Ticuna, que mencionamos acima, no Livro das Árvores, como mostra o texto abaixo:

O buriti é uma palmeira grande, das mais bonitas. Vários buritis formam o buritizal. O dono do buritizal é o Würürü. As frutas do buritizal dão em cacho. Quando amadurecem, ficam escuras e começam a cair. As pessoas, então, podem tirar as frutas para comer. Podem preparar o vinho. E podem vender as frutas na cidade. As frutas também alimentam os animais. Com as folhas novas do buriti, os dançarinos da festa se enfeitam. Com as outras folhas, os homens constroem o cercado do tó cü. Com os braços do buriti, constroem o turi. Com o buriti, as mulheres tecem a esteira da moça-nova. A máscara Mawü carrega talinhos das 
folhas do buriti. As crianças fazem brinquedos com o buriti. As mulheres representam nos pacarás o desenho da casca do buriti. $\mathrm{O}$ buriti serve para dar nome a uma nação. Depois de muito tempo, o buriti cai. No tronco caído cresce o muxiuá. O muxiuá alimenta as pessoas e os animais [...] (TICUNA, 1997, p. 92).

No livro Uasei, o livro do açaí: saberes do povo Karipuna, os Karipuna da aldeia Açaizal do Oiapoque, no estado do Amapá, falam de conhecimentos diversos sobre o açaí, seus usos, jeitos de manejar, consumir e comercializar, restrições de consumo e sua relação com outros elementos do meio ambiente.

O trecho abaixo é um relato do cacique da aldeia, José Damasceno Forte, em que ele resume as utilidades do açaí:

\begin{abstract}
O açaizeiro serve para a construção de casas. Do açaizeiro se tira a folha com a qual se tece; tira também a ripa ou juçara, usada para assoalhar. Serve para esteio e parede de casa. Da folha do açaizeiro se faz jamaxi e outros artesanatos e serve para alguns animais construírem suas casas, como o japim. Também se joga a folha do açaizeiro em cumeeira de casa. A folha é muito utilizada para construir pequenos kabe para se proteger da chuva. Da fruta se faz o vinho, que serve como alimento para a comunidade e se tira o óleo do vinho, que serve para passar no cabelo. Há uma diferença entre açaí da grota e açaí da várzea. O da grota é mais graúdo e seco, não tem muita carne. O da várzea é mais fino e tem bastante carne, faz um vinho cor de sangue. Há dois sabores diferentes, um tem gosto salobro e o outro tem o gosto normal do açaí. (KARIPUNA, 2015, p. 21)
\end{abstract}

Segundo os povos Karipuna (2015), o açaí também pode curar diarreia e malária; com a raiz do açaizeiro se faz remédio caseiro para diarreia e malária. Depois de explicarem uma série de procedimentos, eles o colocam no fogo para assar, tiram o sumo e bebem meio copo.

Os Maxakali, povos indígenas que vivem na região nordeste do estado de Minas Gerais, em seu livro Hitupmã'ax - Curar, apresentam como o seu grupo lida com a saúde, quais os remédios que eles utilizam, os rituais que praticam, além de contar a origem do seu povo. As árvores são citadas em vários trechos do livro, de acordo com a sua função de curar. São explicadas, ainda, quais as partes (casca, folhas e frutos) que devem ser utilizadas, além dos passos para a fabricação dos remédios. Os trechos abaixo retratam a importância de árvores como o jaborandi, jatobá e a goiaba:

O remédio do jaborandi é bom para o resguardo e para a doença de criança. A mulher ganha neném e durante um mês fica de resguardo. Depois termina. Então o marido vai para a floresta tirar jaborandi para trazer para casa para dar à esposa e a si. Então se deve mastigar muito, mas não pode tomar o caldo. Quando a criança adoece e respira com dificuldade, o pai vai tirar jaborandi para trazer para casa, raspar e pôr com água, misturar e coar. Depois dá um pouquinho para ele beber. Então ele vomita, o catarro sai e acaba o cansaço. Então a criança sara. (MAXAKALI, 2008, p. 59-60) 
A casca do pé de jatobá é boa para todas as dores. Para usá-la, vá tirar um pouco de casca e traga para casa. Pique a casca com a faca e depois as lave. Em seguida, ponha para cozinhar até ferver. Tire do fogo e passe para outra vasilha e deixe esfriar. Beba um pouco e guarde o resto para beber depois. Vá tomando até acabar. Então a sua dor acaba e não volta mais. (MAXAKALI, 2008, p.117)

O broto da goiabeira é remédio também para sapinho que dá na boca das crianças. A mãe corta (a folha) e amassa. Depois aperta o seio para pôr leite na folha amassada e passa a mistura na boca da criança. Pronto, o sapinho vai então secar. O broto da folha de goiabeira é bom também para dor no olho. Para isso, pegue a folha, amasse-a de novo e misture com leite materno e com uma pitadinha de sal. Depois disso, embrulhe a mistura em um pedacinho de pano e pingue uma gota no seu olho. Pronto, ele ficará bom. (MAXAKALI, 2008, p. 144)

Um outro ponto bastante comum nos livros utilizados como base para a pesquisa é a relação dos indígenas com que eles chamam de donos das árvores, que são os seres que cuidam da natureza e de tudo que nela habita, como mostram os Ticuna:

\begin{abstract}
A floresta é a coberta da terra. É a casa dos animais. É onde nós vivemos. É onde também vivem outros seres. Alguns desses outros seres nós chamamos de nanatü, que significa "dono", "pai" ou "mãe" das árvores, dos animais, dos peixes, das águas. São seres que cuidam há milhares de anos de tudo que existe na natureza, assim como nós cuidamos de nossos filhos e de nossas roças. O buritizal tem dono, o açaizal tem dono [...]. (TICUNA, 1997, p. 28)
\end{abstract}

Os Kuikuro, povos que vivem na região oriental da bacia hidrográfica do Rio Xingu, em seu livro, também elaboram a relação entre as árvores e seus donos:

O pequi tem dono. Seu dono é o beija-flor de cor preta [...]. Por isso os pequizeiros devem sempre estar limpos e devemos ter cuidado com as árvores de pequi, senão o sono do pequi, o beija-flor de cor preta, ficará bravo e fará mal para você. (KUIKURO, 2007, p. 97)

A copaíba tem seu dono que tem a pintura ionto. Por isso o lutador sempre se pinta com a resina dessa árvore, para o espírito da copaíba ajudar o lutador. Antigamente só os adultos usavam essa resina. Hoje em dia toda a rapaziada se pinta com a resina de copaíba. (KUIKURO, 2007, p. 117)

As árvores além de possuírem donos também possuem espíritos ou entidades que as protegem, como relatam os Kiukuro e os Ticuna:

\footnotetext{
sociedade, o espírito do jatobá fica no céu. [...] (KUIKURO, 2007, p. 114)

O espírito de certas árvores ajuda o trabalho do pajé.

Quando uma pessoa fica doente, chama o pajé.

E o pajé chama o espírito das árvores para curar. O espírito

chega e entra no corpo do pajé.
}

A árvore de jatobá tem espírito para a minha sociedade. Quando tem um pé de jatobá bem grande, ele tem espírito. Quando sai do tronco uma resina bem preta, é um sinal de um espírito muito perigoso, ninguém pode passar ao redor pensando e nem uma pessoa doente pode passar perto dessa árvore [...] Para a minha 
Aí ele canta. Depois vem outro e mais outro.

Se a pessoa está muito mal, é preciso

chamar vários espíritos.

A samaumeira tem espírito.

A chuchuacha tem espírito.

$\mathrm{O}$ cedro tem espírito.

$\mathrm{O}$ açacu tem espírito.

A ucuuba tem espírito.

A seringueira tem espírito.

A maçaranduba tem espírito.

A castanha-de-paca tem espírito.

(TICUNA, 1997, p. 46)

No artigo denominado "Donos demais: Maestria e domínio na Amazônia”, o professor de antropologia do Museu Nacional estuda os diversos significados que este termo pode ter entre os povos indígenas. De uma maneira bem resumida poderíamos dizer que este termo poderia ser entendido como algo "que designa uma posição que envolve controle e/ou proteção, engendramento e/ou posse, e que se aplica a relações entre pessoas (humanas ou não-humanas) e entre pessoas e coisas (tangíveis ou intangíveis)”. (FAUSTO, 2008, p. 330)

As árvores também são utilizadas pelos povos indígenas como remédios. A tabela abaixo mostra a utilização das árvores pelos povos Ticuna para curar doenças como diarreias e dores no corpo entre outras enfermidades.

Tabela 2: Utilidades das árvores como remédios segundo os povos Ticuna

\begin{tabular}{l|l}
\multicolumn{1}{c|}{ Árvore } & \multicolumn{1}{c}{ Utilização } \\
\hline Casca de Chuchuaca & Fraqueza, palidez e reumatismo \\
\hline Casca de Carapanaúba & $\begin{array}{l}\text { É boa para quem sofre dos rins, fígado, anemia e dor no } \\
\text { estômago. }\end{array}$ \\
\hline Casca de Cedro & Dores no corpo, amebas e palidez \\
\hline Casca de Taperebá & Lavar feridas e curar diarréias \\
\hline Casca de Acapurana & $\begin{array}{l}\text { Cura diarreias, feridas e amebas. Também é usada pelas } \\
\text { mulheres depois do parto e durante a menstruação. }\end{array}$ \\
\hline Andiroba & $\begin{array}{l}\text { Das frutas se extraem os óleos para tratar diarreia, tosse, } \\
\text { dores musculares, coceiras e feridas }\end{array}$ \\
\hline Copaíba & $\begin{array}{l}\text { O óleo cura asma, gripe, coqueluche, febre e dor de } \\
\text { cabeça. Serve ainda para passar no corpo e tratar a } \\
\text { coceira }\end{array}$ \\
\hline Açaí & $\begin{array}{l}\text { O chá da raiz é usado para disenteria, dor no estômago e } \\
\text { amebas. }\end{array}$ \\
\hline
\end{tabular}

Fonte: Autoria própria. 
A partir dos exemplos e das relações citados acima, podemos perceber o quanto as árvores são importantes e convivem com o entendimento de mundo dos povos indígenas. Sejam como remédios, seja como presente na própria genealogia destes povos, ou como entidades que possuem seus donos, estas fazem parte da cosmovisão desses povos. Aqui levantamos alguns exemplos que nos serviram como base teórica para pensar as atividades propostas para as dinâmicas de educação ambiental.

Como foi dito acima, a noção de perspectiva, elaborada pelo antropólogo Viveiros de Castro, entende que o pensamento dos povos indígenas se dá na absorção do ponto de vista do outro. As dinâmicas pensadas para este trabalho, tiveram então a intenção de levar os participantes a conhecerem um pouco mais do ponto de vista dos indígenas sobre as árvores, a partir de narrativas destes povos, usos que eles fazem das plantas e noções próprias de suas sociedades como a noção de dono mencionada acima. Assim, no início das práticas, as crianças ouviam histórias indígenas e também eram mostrados a elas, através de desenhos, os donos de cada uma das árvores que estavam nas narrativas.

\subsection{Resultados da execução da proposta de educação ambiental}

Nos dias do evento, estiveram presentes cinco escolas municipais nos períodos da manhã e da tarde, em que cerca de 210 crianças dos 5 aos 14 anos participaram das dinâmicas e oficinas propostas pelo projeto. Como resultado das oficinas, foram obtidos desenhos e frases que mostram o quanto as crianças aprenderam sobre os saberes ambientais indígenas.

Com as crianças dos 5 aos 8 anos, depois de contadas histórias indígenas, explicado o porquê de algumas árvores terem nomes indígenas e o que eles significam nas línguas indígenas (o ipê, por exemplo, vem do tupi e significa árvore de casca), foi feita a observação das árvores. As crianças foram estimuladas a realizarem criações de desenhos e colagens com as folhas das árvores da própria fazenda da Soledade (Figuras 2 e 3). As crianças desenharam as árvores que estavam presentes no local, além de desenharem qual seria o seu “dono" ou animal protetor, de acordo com a perspectiva indígena dos donos das árvores. 
Figura 2: Palmeira Jussara e dono

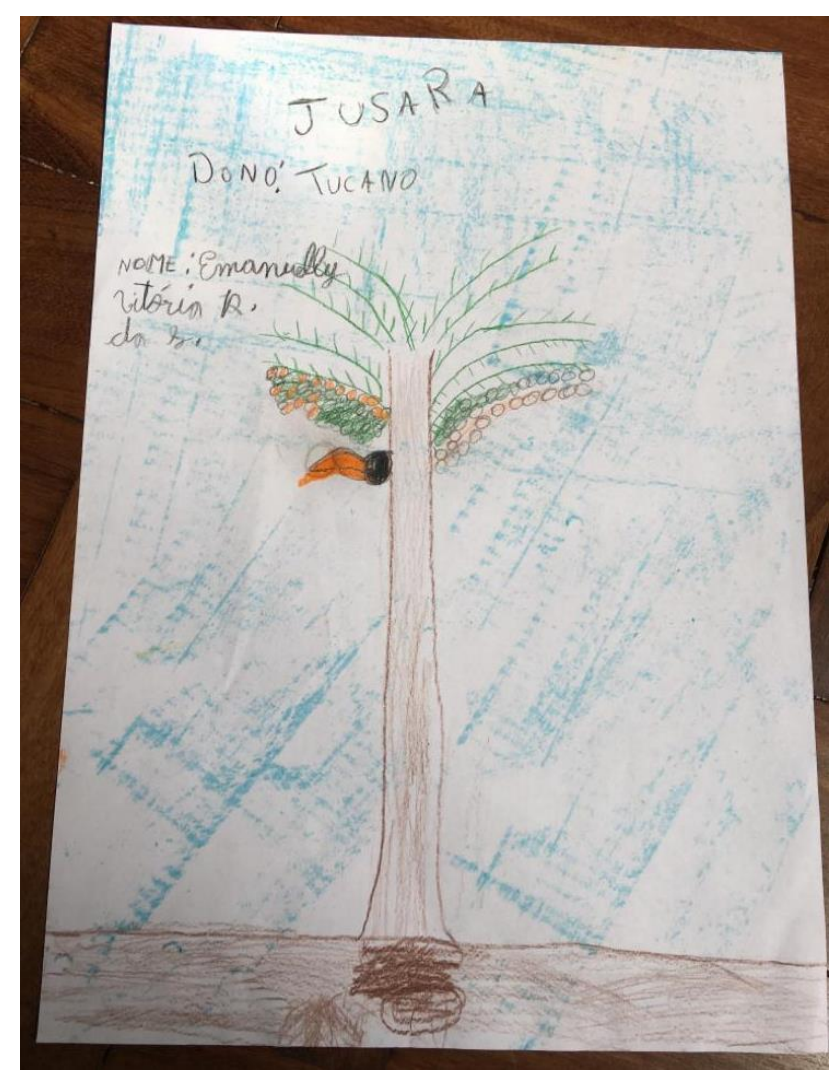

Figura 3: Árvore de Açaí e seu dono

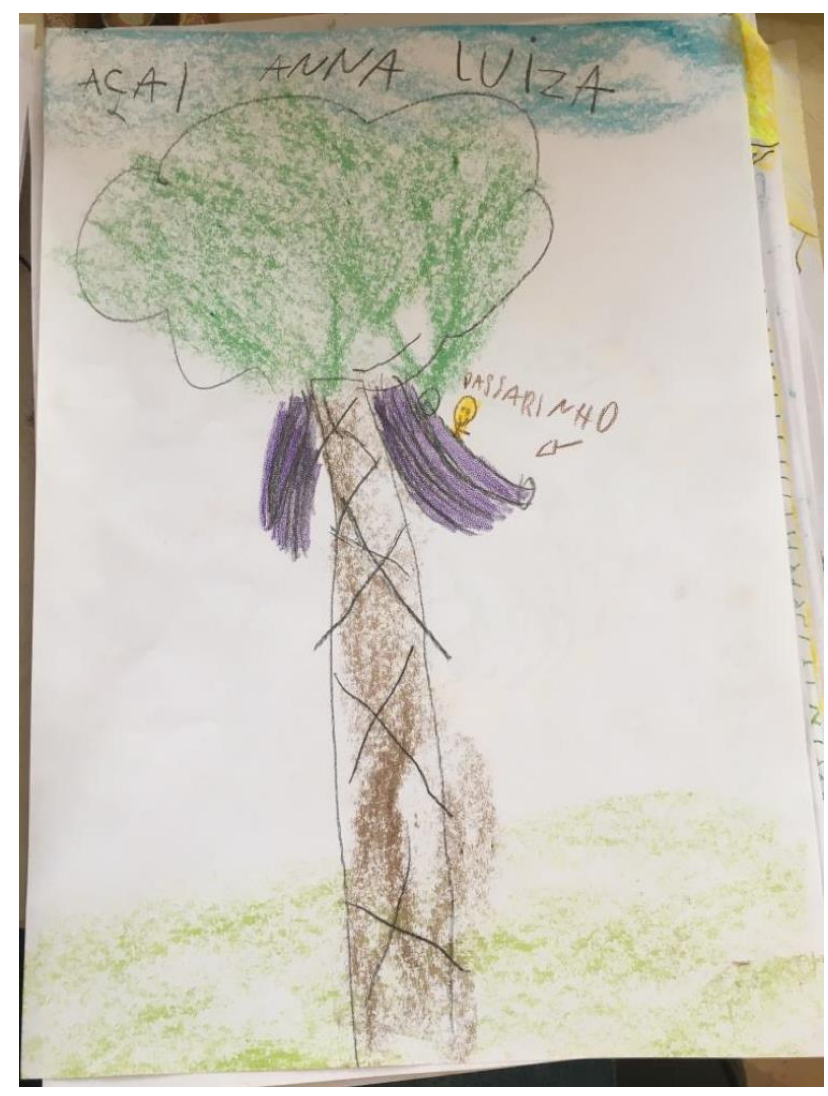


Figura 4: Ipê amarelo e o índio como seu dono

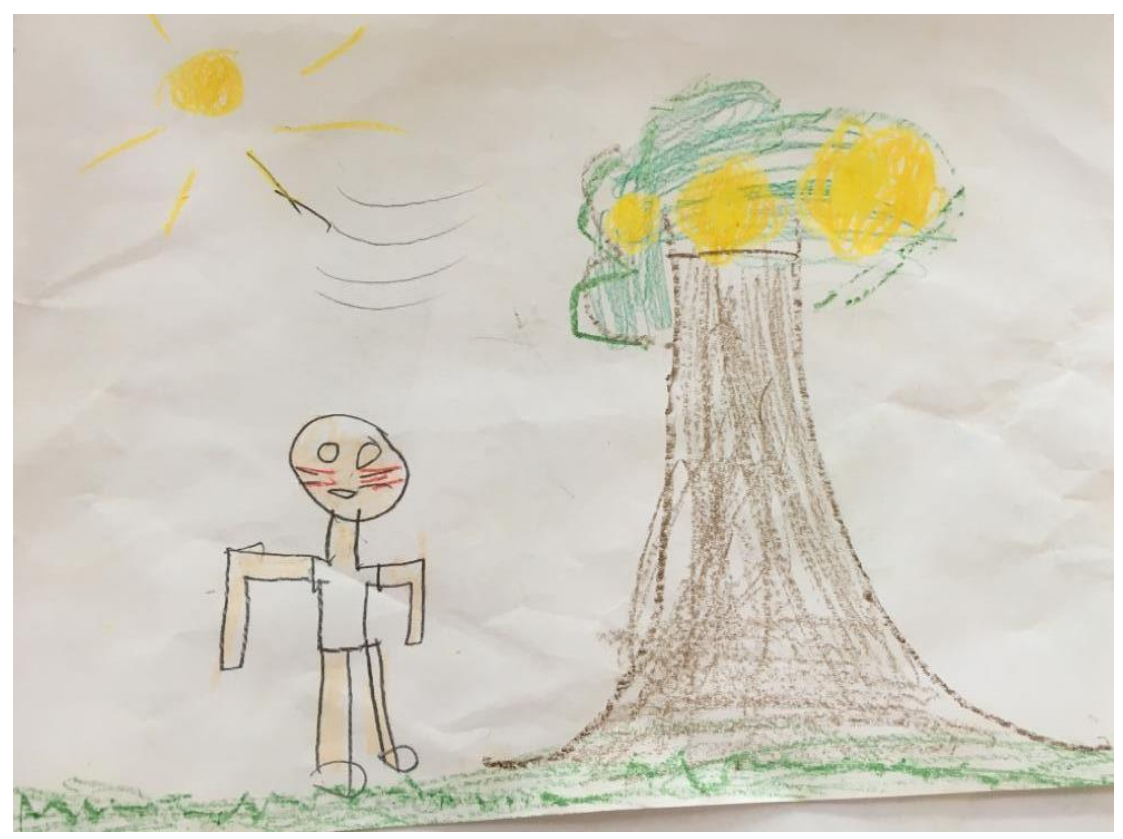

Figura 5: Colagem com flores de ipê amarelo

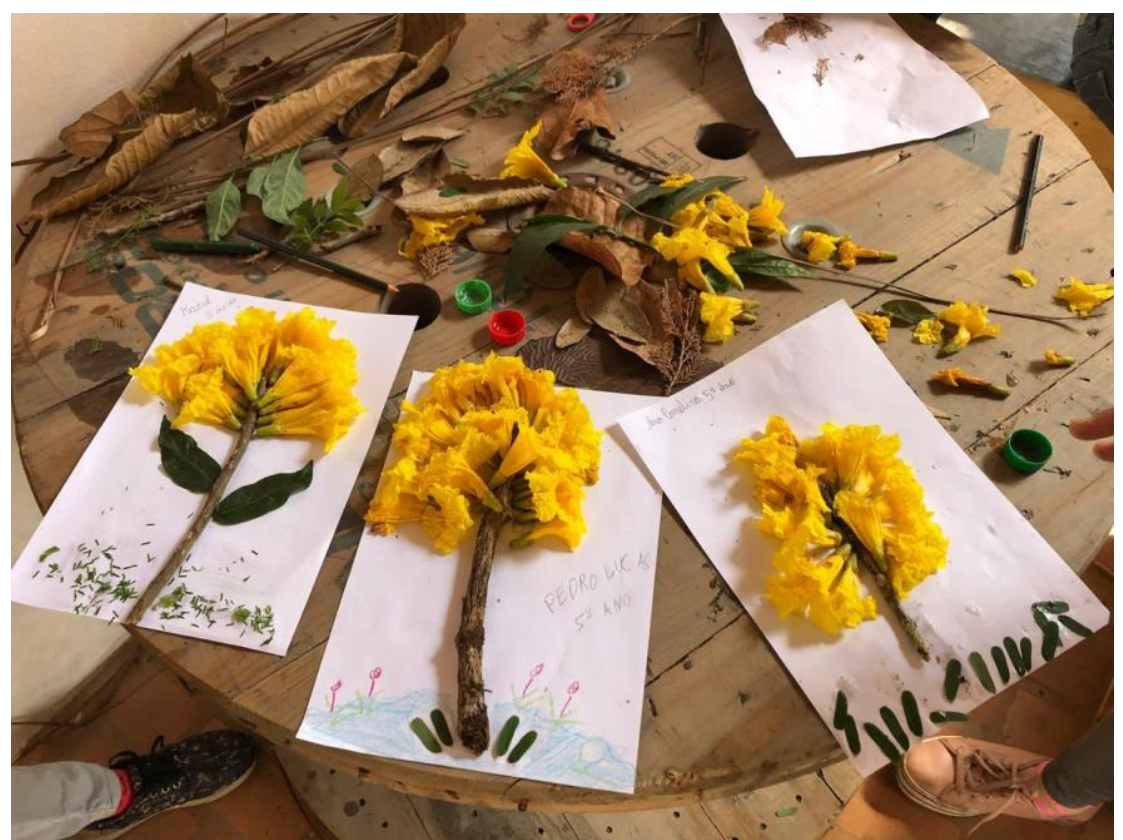


Figura 6: Colagem com folhas de árvores

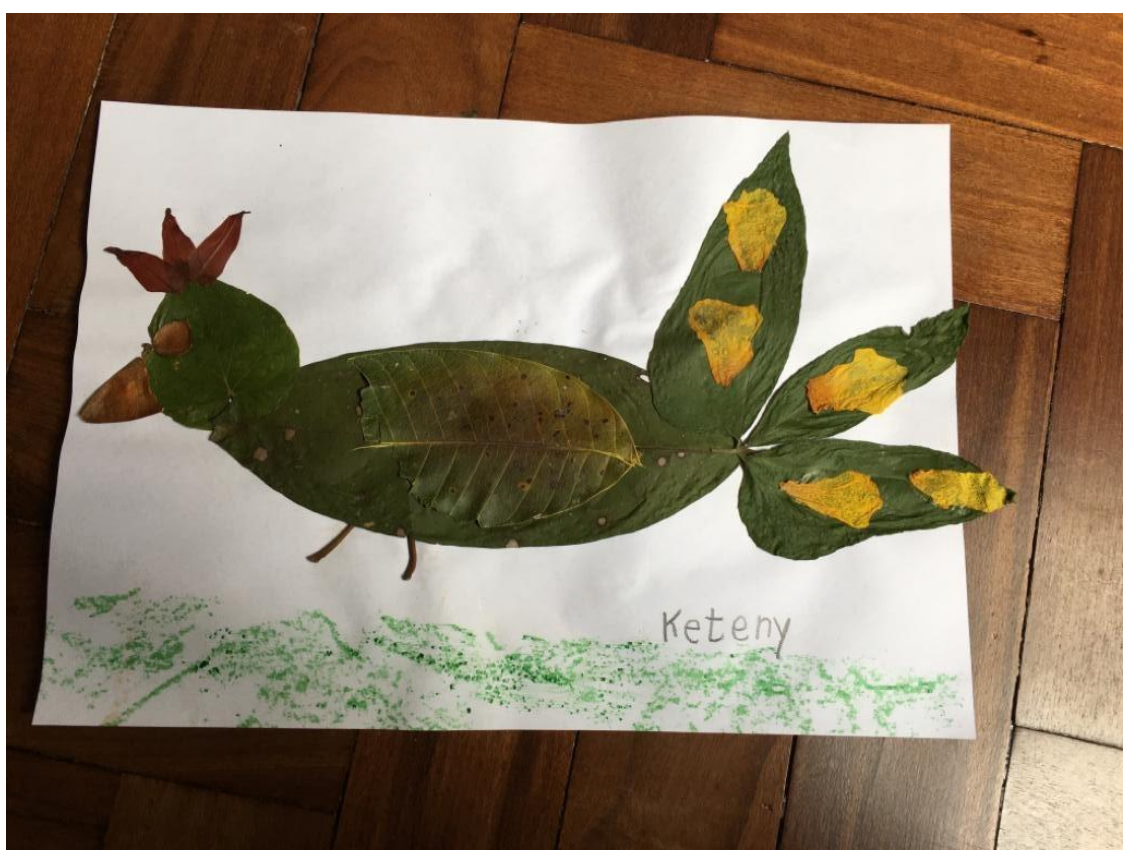

Podemos notar que a noção de dono foi muito importante para as crianças notarem que existem animais mais próximos, que se relacionam com mais presença com cada uma das árvores. No exemplo acima, o aluno entendeu que o dono da palmeira Jussara é o Tucano. Várias foram as árvores observadas e os donos correlatos. Ao final, foram feitas perguntas como: por que será que o Tucano é o dono da Jussara? Será que ele viveria sem ela? E a Jussara viveria sem ele?

Para as crianças dos 9 aos 14 anos, foram feitas dinâmicas mais elaboradas. Em relação aos donos, eles foram estimulados a contar pequenas histórias entre os donos e suas árvores. Após a exibição do documentário "A gente luta, mas come fruta”, foi solicitado que elas elaborassem uma frase que respondesse a seguinte pergunta: Como os índios ajudam a preservar as florestas? As frases que mais condisseram com a pergunta são apresentadas a seguir:

Os índios desde crianças já plantam árvores para dar frutos para eles, além disso eles plantam perto de suas aldeias para protegê-las, quando as árvores dão frutos eles as apanham e levam para as crianças nas escolas.

Os índios plantam suas próprias árvores para que não precisem desmatar e ensinam as crianças a fazerem o mesmo.

Os índios ajudam não cortando as árvores, e sim fazendo muitas plantações para ter os seus próprios alimentos. E sempre cuidando do solo.

Os índios ensinam as crianças a plantarem e sobre as plantas. Eles são importantes para as florestas. 
Os índios ajudam a proteger as florestas fazendo suas próprias plantações e cuidando da terra.

Eles ajudam a proteger as árvores plantando as sementes, não colocando fogo nas florestas, colhendo as frutas. E também ensinam as crianças a plantarem e protegêlas. (Os autores, s.p., 2019)

Com as frases, pode-se observar que as crianças destacaram o plantio das árvores pelos Ashaninka, além do fato de que os adultos transferem o seu conhecimento para os mais jovens, ensinando a plantar e cuidar das árvores que, no futuro, irão lhes propiciar seu alimento.

\section{CONSIDERAÇÕES FINAIS}

As árvores têm muita importância para os povos indígenas. Para os Ticuna, elas deram origem ao lugar em que eles vivem e a sua nação. Elas também são importantes para a fabricação de remédios para várias enfermidades, assim como retratam os Kiukuro e os Maxakalí. A história e a cultura de vários povos se misturam com as árvores, pois é no meio da floresta que os indígenas nascem, crescem e morrem.

Dessa forma, o trecho abaixo resume bem a importância das árvores, não só para os povos indígenas, mas sim para toda a humanidade:

(...) Que as árvores têm muitos significados para nós. Fazem parte da nossa vida, da nossa cultura. As pessoas estranhas, que vêm de fora, não entendem esses significados. Entram na mata e destroem tudo. As árvores, a floresta, não têm sentido para elas. Têm apenas o sentido do lucro que a madeira pode dar. Este livro ajudará a lembrar que cada árvore tem sua importância. Que as árvores formam a floresta. E a floresta é a maior riqueza que deixaremos para nossos filhos. (TICUNA, 1997, p. 92).

Entendemos que a proposta desta prática foi bastante significativa para os alunos que participaram, pois além de conhecerem mais dos povos indígenas brasileiros e de sua importância para nossa sociedade, eles criaram novas percepções sobre as árvores que os circundam, desde a observação de suas folhas, frutos e troncos, até a relação que estas estabelecem com outros seres, tais como os animais.

Por fim, podemos concluir que conhecer outra cultura nos coloca em situação de espelhamento e nos faz refletir sobre a nossa própria cultura. Qual é o valor que as árvores têm para nossa sociedade? Como tem sido a educação em relação às árvores? Também acreditamos que este projeto pode ter vários desdobramentos. Além de nos aprofundarmos 
nessas questões sobre as árvores, incluindo na pesquisa novos livros indígenas e científicos, acreditamos que poderíamos desenvolver a mesma metodologia de "perspectivas" em relação aos animais e às práticas indígenas.

Acreditamos que a dinâmica apresentada aqui é só uma das possibilidades de criação de práticas de educação ambiental no diálogo dos saberes dos povos indígenas com a Engenharia Ambiental, e que, para além das práticas de educação ambiental já saturadas nas escolas, estas poderiam proporcionar novas metodologias de ensino nas escolas nãoindígenas, contando com estes povos que são, definitivamente, povos da floresta.

\section{REFERÊNCIAS}

A GENTE luta mas come fruta. Direção Isaac Pinhanta e Valdete Pinhanta. Acre, Vídeo nas Aldeias, 2006. Online (15 minutos).

BERKES. Fikret, COLDING. Johan, FOLKE. Carl. Rediscovery of Traditional Ecological Knowledge as Adaptive Management. 2000. Disponível em: https://www.fws.gov/nativeamerican/pdf/tek-berkes-2000.pdf. Acesso 25 out. 2019.

CAVALLO. Gonzalo Aguilar. Conhecimentos ecológicos indígenas e recursos naturais: a descolonização inacabada. 2018. Disponível em: http://www.scielo.br/scielo.php?script=sci_arttext\&pid=S0103-40142018000300373. Acesso 25 out. 2019.

CASTRO, Eduardo Viveiros de. Os pronomes cosmológicos e o Perspectivismo Ameríndio. Revista Mana 2 (2): p. 115-144, 1996.

DANOWSKI, Débora. CASTRO, Eduardo Viveiros. Há mundo por vir? Ensaio sobre os medos e os fins. Florianópolis, Desterro, Cultura e Barbárie e Instituto Socioambiental, $2014.176 \mathrm{p}$.

FAUSTO, Carlos. Donos demais: Maestria e domínio na amazônia. Rio de Janeiro, Revista MANA, 14 (2), p. 329-366, 2008.

KARIPUNA. Usaí, o livro do Açaí: saberes do povo Karipuna. Ana Paula Nóbrega da Fonte (org.). Luís Donisete Benzi Grupioni (ed.). São Paulo: Iepé - Instituto de Pesquisa e Formação Indígena, 2015.

KUIKURO, Índios. KUNGATAGOHOHA IGEI NGONGOI: esta é a terra que nós plantamos. Belo Horizonte: Faculdade de Letras/UFMG, 2007.

ISA, Instituito Sócio Ambiental. Demarcação de Terras Indígenas é decisiva para conter o desmatamento e regular o clima. Disponível em: https://www.socioambiental.org/pt-br. Acesso em: 22 mar 2020. 
LARA. Robriane, WEISE, Angélica. A Importância das Árvores para o Planeta. 2018. Disponível em: https://www.dimensaodanatureza.com/single-post/a-importancia-dasarvores-para-o-planeta. Acesso em: 26 out 2019.

LORENZI, Harri, Árvores brasileiras: manual de identificação e cultivo de plantas arbóreas do Brasil. vol.1. 4.ed. Nova Odessa, SP: Instituto Plantarum, 2002.

MAXAKALI, Povo. Hitupmã'ax: Curar. Belo Horizonte: Faculdade de Letras/UFMG; Edições Cipó Voador, 2008.

LEVI-STRAUSS, Claude. O pensamento selvagem. Trad. Maria Celeste da Costa e Souza e Almir de Oliveira Aguiar. 2. ed. São Paulo: Ed. Nacional, 1976.

RISÉRIO, Antonio. Textos e tribos: poéticas extraocidentais nos trópicos brasileiros. Rio de Janeiro: Imago, 1993.

TICUNA. O livro das árvores. 4. ed. São Paulo: Global, 1997. 